\title{
Relying on reference cases when evaluating new technical solutions? Evaluation of technical documentation in a case study.
}

\author{
Charlotte Svensson Tengberg ${ }^{1,2^{*}}$, and Carl-Eric Hagentoft ${ }^{1}$ \\ ${ }^{1}$ Chalmers University of Technology, Department of Architecture and Civil Engineering, Gothenburg, Sweden \\ ${ }^{2}$ Skanska Sverige AB, Gothenburg, Sweden
}

\begin{abstract}
Serial failures have occurred when introducing new technical solutions in the Swedish construction industry. In an earlier interview study exploring introduction of new technical solutions, documentation and reference cases provided by the supplier are given as the main sources for evaluation. This paper aims at addressing the questions: 1. What kind of documentation concerning building physics are provided by suppliers? 2. How well does the suppliers' documentation meet the need for verification? In order to address these questions, the case of hygrothermal performance of cross laminated timber structures in multifamily dwellings was chosen. An inquiry of data was sent out to four suppliers at the Swedish market, asking for documentation and reference cases provided. Based on the documentation given, an assessment was made of to which extend the documentation can support verification of appliance to the relevant requirements of the Swedish building regulations. The case study shows reference cases are scarce and existing documentation is not comprehensive, thus indicating the building industry might have a disproportional high confidence in reference cases. The results will be used to suggest requirements for reference cases to be used for verification.
\end{abstract}

\section{Introduction}

To successfully introduce new technical solutions in the construction industry is a challenging task. There are examples in the Swedish construction industry of both too slow adaptation of new technical solutions, e.g. loss of competitiveness and not achieving the anticipated benefits, and of too fast adaptation, e.g. poor quality and failure as the functional requirements are not sustained.

New technical solutions that have resulted in serial failure in Sweden involve new materials, new products, new designs or new processes. There are plenty of examples of a known solution introduced in a new application with new boundary conditions resulting in failure e.g. [1] and [2]. Two infamous examples of serial failures in Sweden during the last two decades are: The introduction of magnesium boards where a new material with insufficient documentation on material properties was used in applications with high moisture conditions which caused moisture uptake of the material and corrosion of adjacent materials. The other example is the introduction of ETICS ${ }^{\text {a }}$ on stud frame walls, where the new application on stud frame walls created a sensitive design with respect to workmanship and moisture causing mould growth.
In a previous interview study with key actors in the Swedish construction industry, the suppliers were found to be the main drivers of introducing new technical solutions as well as the main source of information on the new solutions [3]. However, in a study on flooring and related products, a lack of available verified product properties concerning building physics from the suppliers was identified [4]. Also, the product data identified in the study was often old, deterministic, determined for one single condition. Previously, similar gaps in moisture related material properties had been observed in [5].

A research project has been initiated with the overall aim to establish a methodology to reduce the risks of serial failure related to building physics when introducing new technical solutions in the construction industry. The aim of this paper is to create a better understanding of the potential of available documentation for verification of new technical solutions with respect to building physics. Two questions were formulated:

- What kind of documentation concerning building physics are provided by the suppliers?

- How well does the suppliers' information meet the need for verification of the solution in a building?

${ }^{a}$ External Thermal Insulation Composite System

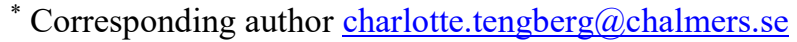


This study is limited to the case study of one technical solution: cross-laminated timber structures in multi-family dwellings in Sweden. No actual verification of the technical solution is made.

\section{Method}

A case study was performed to evaluate available documentation for verification of a specific new technical solution with respect to functional requirements in the building regulations concerning building physics. The identified documentation was evaluated as to usability to verify functional requirements in the case study.

\subsection{Selected case: Cross-laminated timber}

Cross-laminated timber frames in multi-family dwellings were chosen to represent the application of a new technical solution. Cross-laminated timber (CLT) is made of layers of lumber wood glued together crosswise. A CLT board has typically three, five or seven orthogonal layers of lumber wood each of 20 to $45 \mathrm{~mm}$ thickness [6]. The technical solution was introduced in building frames with given benefits such as good environmental performance, renewable material, light material, short construction time and possibilities of offsite production and good workability at site [6]. Crosslaminated timber originates from central Europe Austria, Germany, Switzerland - in the early 1990-ies. The CLT technique enabled a refined product from the use of sawmill by-products, i.e. side boards, thus creating a new market [7]. During the 1990-ies extensive research were carried out, especially with focus on structural aspects [8], and the first residential buildings were built in the mid 1990-ies. According to [8] the earliest European buildings with CLT walls were built in 1993. According to [9] the earliest building in Sweden was in 1995, and a few more buildings followed during late 1990 -ies and early 2000 -ies. The last 10 years there has been a significant increase in the use of CLT, in Sweden and as well as internationally.

Cross-laminated timber was selected as a study case as it is an example of a quite recently introduced technical solution with large impact on the Swedish construction industry. Furthermore, in a previous interview study [3], some of the interviewees also raised concerns regarding risks of exceeding critical moisture conditions in the CLT structure.

In an earlier phase of this project, a risk assessment has been performed according to a framework for risk assessment [10] with the scope of fulfilling functional requirements related to building physics using a crosslaminated timber frame in a multi-dwelling building [11]. The risk identification identified moisture during the construction phase as the most critical risk. Furthermore, the following most important uncertainties or unknowns relevant for suppliers' documentation were also identified:
- Performance of products

- Hygrothermal behaviour of building envelope components

- Moisture exposure and loads during construction phase

- Effects of rain water leakage during construction phase

Other aspects identified were Compliance to design and moisture routines, Knowledge in organisation and Responsibility of different actors.

\subsection{Functional requirements and verification}

Demands from the society in Sweden affect the building sector at different levels. The demands are expressed at different levels: as laws $\left(\mathrm{PBL}^{\mathrm{b}}\right)$, as regulations $\left(\mathrm{PBF}^{\mathrm{c}}\right)$, as provisions $\left(\mathrm{BBR}^{\mathrm{d}}\right.$ and $\mathrm{EKS}^{\mathrm{e}}$ ) and as general advice (in BBR and EKS). Also, in compliance with EU, all products which are subject to a harmonized standard should have a CE-marking in order to be sold. There are also laws affecting the construction phase, e.g. concerning work safety.

Generally, concerning fulfilment of functional requirements in BBR during the design stage, there are general advice on calculations (quantitative assessment) and proven solutions. For moisture safety design, there is an additional general advice on qualitative assessment:

a) Calculations (quantitative assessment). Calculations can be used in design but note the importance of using a model with a good representation of the actual case during service life as well as representation of variations in execution.

b) Proven solutions. It should be ensured the prerequisites of the actual case follow the proven solution or should the consequences of the differences be negligible. Materials and products should have known and documented properties.

c) Qualitative assessment. This is expressed as qualitative assessment of the solution in comparison to other solutions in e.g. handbooks or other instructions (evaluated by quantitative assessment or as proven solutions).

Furthermore, the general advice states the result of the design should be documented to verify that the requirements are fulfilled. Verification should be made in design, in construction or in-service life. There is no explicit general advice on how the requirement management should be managed, e.g. how to perform and document breakdown of requirements or traceability.

\subsection{Requested documentation}

Documentation to be requested from suppliers was defined in relation to fulfilment of functional requirements concerning building physics in the building

\footnotetext{
${ }^{b}$ PBL (2010:900) with changes until SFS 2018:1732

${ }^{c}$ PBF (2011:338) with changes until 2018:1872

${ }^{d}$ BFS 2011:6 with changes until BFS 2018:4

${ }^{\mathrm{e}}$ EC Eurocodes
} 
regulations together with results from a risk identification workshop based on the chosen technical solution [4]. The following data were identified to be relevant to be either provided or to be assessed to be neglectable in a reference case.

- Loads: Outdoor climate, Micro climate, Indoor climate

- Design of building components: Material layers, Geometry, Detailing, Material properties

- Process: Weather protection, Length of exposure

- Organisation: Experience of staff, Allocated resources, Available knowledge

- Documented performance: Hygrothermal verification of building components and details, verification methods

As verification of a technical solution can basically be made by calculations (quantitative assessment) or by proven solutions, the requested data were divided into two main categories:

- Quantitative assessment: Product properties related to building physics, see Table 1 .

- Proven solutions: Handling instructions, design solutions and reference cases, see Table 2.

In addition, some general documentation on design of elements was requested to better define the product, e.g. sort of wood and glue, thicknesses of layers and products, tolerances and labelling.

\subsection{Sources of information}

The main source of product documentation is the suppliers of the relevant products. Furthermore, a literature search on related data was performed.

\subsubsection{Suppliers of cross-laminated timber}

Four well-established suppliers of cross-laminated timber were contacted. The suppliers were selected as four relevant actors in Sweden. The case and requested documentation were presented by phone, directly followed up by an e-mail containing the same information and an excel sheet. All the suppliers agreed to participate, however one of them failed to present relevant documentation in three months despite several reminders and was therefore excluded.

The requested data were explicitly defined in an excel sheet; however, the suppliers were instructed to submit other related information or references if they did not have the explicit data requested. In the end, all data were compiled in a final table for each supplier and distributed to the suppliers respectively for possible completion.

\subsubsection{Literature and other sources}

In parallel to the input from the suppliers, a literature search was performed to establish knowledge of the research community on product properties of CLT and the performance of CLT structures in construction with focus on building physics. Using Scopus database to identify articles concerning CLT and hygrothermal performance resulting in 21 relevant articles, and by snowballing adding another 9 articles resulting in 30 relevant articles, including measurements and simulations of hygrothermal performance of CLT and/or CLT structures. The documents are quite recent, more than half of them dated 2018 or 2019, implying an increased interest for the topic and on-going research. Also, available handbooks and other relevant material were identified.

\section{Results}

Documentation from suppliers and other sources are presented below.

\subsection{Documentation from suppliers}

The main task was to identify available documentation from suppliers.

\subsubsection{Product properties}

There is at present no harmonised standard for solid wood slab elements, but as there is a European assessment document: EAD 130005-00-0304 ${ }^{\mathrm{f}}$ : Solid wood slab element to be used as a structural element in buildings (2015). Thus, there is a possibility for the suppliers to get an ETA $^{\mathrm{g}}$ issued and to have a CE marking of the product. Two of the suppliers have an ETA, the other has a "Typgodkännande" (a Swedish system for products without a harmonised standard). The slabs provided by the suppliers are similar in structure and from the level of detailing of data given, no significant differences can be detected. For example, adhesive is defined as "PUR" by all the suppliers.

The submitted data on product properties concerning building physics are summarised in Table 1 . The answers concerning building physics properties of the products corresponds with the requested data in the EAD. Other aspects were rarely covered. It should also be noted, all given data were deterministic. Some notes on product properties:

- None of the suppliers have provided documentation on critical moisture level. The EAD/ETA only support issues on durability of timber.

- Specific documentation on porosity, water storage functions or liquid transport are not provided.

- Water vapour diffusion resistance is given as a function of moisture content ("wet" and "dry"). Only one of the suppliers defines the water vapour diffusion resistance of the adhesive. The given values are well in line with spruce, except for the values containing adhesive which are slightly higher for wet conditions.

- The slab is given to be air tight from three layers.

\footnotetext{
${ }^{f}$ EAD: Technical Assessment Document www.eota.eu

${ }^{g}$ ETA: European Technical Assessment www.eota.eu
} 
- A change in shape with change in moisture content is given for the slab. One supplier states a significantly lower perpendicular value than commonly used for spruce.

- Thermal conductivity and specific heat capacity are given. Thermal conductivity is slightly lower than commonly used for spruce.

Table 1: Suppliers' data: Product properties related to building physics. Light green: unspecified data/external reference.

\begin{tabular}{|c|c|c|c|c|}
\hline & Supplier 1 & Supplier 2 & Supplier 3 & EAD 130005-00-0304 \\
\hline \multicolumn{5}{|l|}{ Parameter } \\
\hline Density & $470 \mathrm{~kg} / \mathrm{m}^{3}$ & $470 \mathrm{~kg} / \mathrm{m}^{3}$ (spruce at $12 \% \mathrm{MC}$ ) & $430 \mathrm{~kg} / \mathrm{m}^{3}$ & No info \\
\hline Porosity & No info & No info & No info & No info \\
\hline $\begin{array}{l}\text { Water vapour diffusion } \\
\text { resistance }\end{array}$ & $\begin{array}{l}50 \text { (dry) - } 20 \text { (wet) }[-] \\
\text { moisture dependant }\end{array}$ & $\begin{array}{l}70 \text { (dry) - } 40 \text { (wet) [-] } \\
\text { moisture and layer dependant }\end{array}$ & $\begin{array}{l}50 \text { (dry) - } 20 \text { (wet) }[-] \\
\text { moisture dependant }\end{array}$ & According to EN10456 \\
\hline Moisture storage functions & No info & No info & No info & No info \\
\hline Liquid transport coefficient & No info & No info & No info & No info \\
\hline Air tightness & airtight from 3 layers & airtight from 3 layers & airtight & $\begin{array}{l}\text { According to EN12114. Testing and declaration of } \\
\text { results. }\end{array}$ \\
\hline Critical moisture level & No info & No info & No info & $\begin{array}{l}\text { (Durability of timber assessed according to EN335, } \\
\text { table 1, EN350-2, Table } 2 \text { and EN460.) }\end{array}$ \\
\hline $\begin{array}{l}\text { Change in shape with change in } \\
\text { moisture content }\end{array}$ & $\begin{array}{l}\text { panel layer: } 0.02 \% / \% \mathrm{MC} \\
\text { perpendicular: } 0.24 \% / \% \mathrm{MC}\end{array}$ & $\begin{array}{c}\text { panel layer: } 0.01 \% / \% \mathrm{MC} \\
\text { perpendicular: } 0.025 \% / \% \mathrm{MC}\end{array}$ & $\begin{array}{l}\text { panel layer: } 0.01-3 \% / \% \mathrm{MC} \\
\text { perpendicular: } 0.2 \% / \% \mathrm{MC}\end{array}$ & $\begin{array}{l}\text { "The dimensional changes of the solid wood slab } \\
\text { due to varying moisture content shall not have } \\
\text { inadmissible effects on its performance and } \\
\text { stability. " }\end{array}$ \\
\hline Moisture content (at delivery) & $12 \% \mathrm{MC} \pm 2 \% \mathrm{MC}$ & $12 \% \mathrm{MC} \pm 2 \% \mathrm{MC}$ & $12 \% \mathrm{MC}$ & $\begin{array}{l}\text { "The moisture content at the time of shipping } \\
\text { shall be declared by manufacturer." }\end{array}$ \\
\hline Thermal conductivity & $0,11-0,12 \mathrm{~W} /(\mathrm{mK})$ & $0,12 \mathrm{~W} /(\mathrm{mK})$ & $0,12 \mathrm{~W} /(\mathrm{mK})$ & Declaration of design values according to EN10456 \\
\hline Specific heat capacity & $1600 \mathrm{~J} /(\mathrm{kgK})$ & $1600 \mathrm{~J} /(\mathrm{kgK})$ & $1600 \mathrm{~J} /(\mathrm{kgK})$ & Declaration of design values according to EN10456 \\
\hline
\end{tabular}

\subsubsection{Handling instructions, design solutions and reference cases}

The answers on handling instructions, design solutions and references cases, are summarised in Table 2 . Concerning issues related to handling instructions, there are low support on these issues in the EAD where only service life and service classes are found to be relevant to the scope. This might be a reason to the finding that information on handling of products given by the suppliers is only general information. Furthermore, the three suppliers mainly act as product suppliers, thus these issues not normally handled by them.

The instructions for handling of the products with respect to moisture are qualitatively expressed by the suppliers as variants of: "protect from weather conditions" and: "take note of weather conditions while unloading". One of the suppliers state the product: "...can come briefly into contact with water." without quantification of e.g. exposure time or amount of water. One quantitative measure is given by two of the suppliers, a maximum moisture content of $18 \% \mathrm{MC}$ before installing additional layers.

Concerning references of building components and detailing, two of the suppliers have elaborated solutions for this. The solutions come with documentation on some aspects, e.g. thermal performance. The other suppliers give reference to building components and details from an external source, [6].

Concerning references of existing buildings, two of the suppliers give references of buildings, whereof only one has some information related to construction. However, the references contain no documented evaluation or verification. Instead typical data are name, location, year of construction, type of building, involved actors, pictures of building and construction and used CLT products. 
Table 2: Suppliers' data: Handling instructions, design solutions and reference cases related to building physics. Light green: unspecified data/external reference.

\begin{tabular}{|c|c|c|c|c|}
\hline & Supplier 1 & Supplier 2 & Supplier 3 & EAD 130005-00-0304 \\
\hline \multicolumn{5}{|l|}{ Parameter } \\
\hline $\begin{array}{l}\text { Material, handling } \\
\text { instructions (transport) }\end{array}$ & $\begin{array}{l}\text { Must be protected from direct } \\
\text { weathering. Can come briefly into } \\
\text { contact with water. }\end{array}$ & $\begin{array}{c}\text { Wrap elements. Take note of } \\
\text { weather conditions while unloading. }\end{array}$ & Protect from precipitation and water. & No info \\
\hline $\begin{array}{l}\text { Material, handling } \\
\text { instructions (storage) }\end{array}$ & $\begin{array}{l}\text { Must be protected from direct } \\
\text { weathering. Can come briefly into } \\
\text { contact with water. }\end{array}$ & Protect from weather conditions & Protect from precipitation and water. & No info \\
\hline $\begin{array}{l}\text { Material, handling } \\
\text { instructions (construction) }\end{array}$ & $\begin{array}{l}\text { Must be protected from direct } \\
\text { weathering. Can come briefly into } \\
\text { contact with water. }\end{array}$ & $\begin{array}{l}\text { Avoid water logging, maximum } \\
18 \% \mathrm{MC} \text { when built in. }\end{array}$ & $\begin{array}{l}\text { Detailed instructions for different } \\
\text { approaches for weather protection, } \\
\text { including verification. Reference to } \\
\text { maximum } 18 \% \mathrm{MC} \text { when built in. }\end{array}$ & No info \\
\hline References, construction & No info & Yes. No given validation & No info & No info \\
\hline $\begin{array}{l}\text { Suggested building } \\
\text { components }\end{array}$ & Applicable solutions & Applicable solutions & External reference & No info \\
\hline Suggested details & Applicable solutions & Applicable solutions & External reference & No info \\
\hline Maintenence instructions & $\begin{array}{l}\text { Protect from moisture. Optimal 40- } \\
60 \% \mathrm{RH} \text {. Service class I and II }\end{array}$ & Service class I and II & $\begin{array}{l}\text { Consider variations in climate. } \\
\text { External reference to service class I } \\
\text { and II. }\end{array}$ & $\begin{array}{l}\text { Intended use } 50 \text { years. } \\
\text { Service classes according } \\
\text { to EN1995-1-1 clause } \\
\text { 2.3.1.3 shall be given. } \\
\end{array}$ \\
\hline References, buildings & Yes. No given validation & Yes. No given validation & No info & No info \\
\hline
\end{tabular}

\subsection{Literature and other sources}

Scientific literature, handbooks and webpages were used to identify other available data on product properties and on handling instructions. For cross-laminated timber, there are research studies on hygrothermal product properties and hygrothermal field studies of buildings with CLT structure.

\subsubsection{Product properties}

There are studies dealing with determining hygrothermal properties of different types of CLT, e.g. [12-14]. In [15] property data for hygrothermal simulations of CLT are suggested, based on earlier research at National Research Council of Canada and FPInnovations. The material database of WUFI [16] contains product properties for two suppliers' products. The values are similar to data given by other suppliers.

In the CLT-handbook, US-edition [17], the only specific CLT product property given relevant to moisture performance is the water vapor permeability which expressed as water vapor diffusion resistance varies from 1850 at $10 \% \mathrm{RH}$ to 22 at $90 \% \mathrm{RH}$ (with reference to research from NRC in Canada). Other parameters given are generic values for wood or similar references. Also in the Guidelines from Holzforchung Austria [18], the water vapor diffusion resistance is given for the glue (PUR), expressed as equivalent to spruce: 2-10 mm (dry) or $7-19 \mathrm{~mm}$ (wet). The corresponding Swedish handbook, KL-trähandbok [6] does not give values for these moisture related parameters.

\subsubsection{Handling instructions, design solutions and reference cases}

A few studies address full scale field measurements. One of these reports [19], confirms high moisture levels during exposure in construction when monitoring a 8storey mass timber building in Oregon, US. The drying rate of CLT was reduced by application of impermeable membranes of roof and floor panels. In measurements of a test wall soaked in water in [20] it is concluded that wetted material seem to dry out within a month to a level at least below saturation, in summer/fall conditions in Ontario, Canada, if the moisture is not trapped by other materials. However, another field study [21], show a more severe wetting and longer drying out time. In [22], the wetting and drying performance of different wood products and CLT is stated to have slower wetting and drying potential. From the study, the importance of appropriate on-site moisture management is emphasized. All three of the later references point out the strong influence of wall assemblies on the drying out potential. Field observations of moisture trapping connections with higher moisture levels and poorer drying in [23], and suggests preventative approaches in design, fabrication and construction. The authors also call for redundancy due to variations.

Few studies of field measurements on mould growth are published. In a Swedish report [24], four buildings were studied during construction, concluding CLT will exceed critical moisture levels if no weather protection is used. It is noted that cracks, joints and cavities are most exposed to mould growth.

There is a lack of articles on field measurements on buildings constructed with full weather protection. An exception is [25], where six years of field measurements 
show the CLT walls performs well as to hygrothermal performance throughout the time period studied construction and service life.

The CLT-handbook, US-edition [17], states "CLT panels, similar to other wood products, should always be protected from exposure to rain, snow, and wet ground during transport, jobsite storage, and construction process ...". This is suggested to be achieved with e.g. minimizing exposure time, temporary protection of panels and swift installing of exterior protection (i.e. WRB). Furthermore, it emphasizes on the vulnerability of end grains and gaps between the panel laminations as well as the benefits of vapor permeable membranes to allow drying out. The corresponding Swedish handbook, KL-trähandbok [6] refer to general requirements in the building regulations, and refer to a maximum of $18 \% \mathrm{MC}$ before built-in and notes that a calculation may be performed to assess the design as to condensation within the building component. There are also compilations of reference cases, e.g. [9] and [26]. However, no documentation on evaluation are provided to these reference cases.

Altogether, the literature search shows some recent reports from field measurements of moisture performance of CLT structures during the construction phase, where all but one are erected without full weather protection. Commonly, the reports stress the significance of enabling the drying out of CLT after erection, and the related problems with moisture trapping design and detailing. Field studies of mould growth is only performed in [24]. The CLT-handbook, US-edition [17] does only consider decay, not mould growth. KLträhandbok [6] refer to general requirements in the building regulations.

\section{Discussion}

The two questions of this study were partly answered.

\subsection{What kind of documentation concerning building physics are provided by the suppliers?}

Typical documentation in the case study is product properties specified in the EAD, instructions for construction together with suggested designs/detailing and names of reference buildings.

Product properties. The given product data are with some exceptions similar from the different suppliers and from literature and often similar to generic wood data. The properties defined in the EAD reflects the provided data. Only deterministic data are provided. Critical moisture levels are not given.

Instructions for construction. Both suppliers' data and other literature state elements should be protected from precipitation and water. However, there are no actual definition or quantification of the critical moisture conditions, neither for the material nor the designs or processes. Only maximum built-in moisture levels are quantified, usually $18 \% \mathrm{MC}$.

Reference designs and buildings. Suppliers give or refer to external sources as to applicable solutions for building components and details. The suppliers provide reference buildings, however only providing descriptive information such as name of building and, in many cases, names of developer and other actors involved.

\subsection{How well does the suppliers' information meet the need for verification of the solution in a building?}

In the case study, the documentation typically provided by suppliers concerning building physics is not sufficient to solely verify fulfilment of functional requirements of the technical solution. It was suggested for a reference case to provide loads, design of building components, processes, organisation and documented performance in order to be used to verify fulfilment of functional requirements concerning building physics. However, there were significant gaps in the documentation:

- Lack of some specific product properties to perform a quantitative assessment or to verify similarity for using reference cases. Some of the suppliers' data need to be filled in with generic data for wood. Especially the lack of documentation on critical moisture level for the specific products, where, in order to assess risk of mould growth from the hygrothermal conditions, the suppliers' data needs to be filled in with generic data for wood or to use $75 \% \mathrm{RH}$ as a limit. Additionally, as all the given data are deterministic, e.g. the variance of parameters must be estimated.

- Lack of documentation from the suppliers on performance concerning moisture during construction phase. There is a lack of product properties on how precipitation affects the CLT structure regarding wetting and drying, and at the same time a lack of documented experiences on how the CLT is affected at site. Thus, the users need to look up any possible documentation or verification of the given reference cases or decide on adequate level of weather protection on other basis.

- Lack of documentation from the suppliers on hygrothermal performance of building components during operation. In order to use the reference cases as proven solutions or as basis for a qualitative evaluation, the users themselves needs to look up any possible documentation or verification of the given reference cases.

There are research results covering parts of the information needed for verification of performance of the solutions in a building. A challenge is to make the applicable results for different products easily available to the construction industry.

\section{Conclusions}

There are gaps in suppliers' provided product data and a lack of suppliers' provided reference cases with corresponding documented verification. The gaps might be partly due to that the suppliers in this study mainly act 
as product suppliers, and only occasionally as subcontractors for the CLT structure.

It can be concluded from the results that the building industry might have a disproportional high confidence in the product suppliers providing data for full verification of construction and operation of a CLT structure with respect to building physics.

It is expected that the way forward is to collaborate in order to make relevant product data and applicable research results easily accessible to the construction industry.

\subsection{Further studies}

Future work will concern further work on elaborating suggested requirements for reference cases to be used for verification of the new technical solution. The relative importance of different parameters on the moisture performance will be estimated to define a framework for helping suppliers to provide adequate reference cases to be used for validation of new technical solutions. Furthermore, it is of interest to also study other examples of new technical solutions and corresponding documented verification.

Support from the Development Fund of the Swedish Construction Industry (SBUF) is gratefully acknowledged.

\section{References}

1. Samuelson, I. Forty years of building physics research - for what benefit? in 9th Nordic Symposium on Building Physics, Tampere (2011). doi:ISBN 978-952-15-2573-5

2. Samuelson, I., Arfvidsson, J. \& Hagentoft, C.-E. Få bukt med fukt. (Formas, 2007).

3. Svensson Tengberg, C. \& Hagentoft, C.-E. Introducing New Technical Solutions in the Swedish Construction Industry - Interviews with Key Actors. in ASHRAE Thermal Performance of the Exterior Envelopes of Whole Buildings XIV International Conference 810-817 (ASHRAE, 2019).

4. Eliasson, M., Svensson Tengberg, C. \& Larsson, T. Fuktegenskaper för golvkonstruktioner. Materialegenskaper. (SBUF, 2018).

5. Åhs, M. Fuktegenskaper för byggnadsmaterial - en litteraturstudie. (Lund University / SBUF, 2012).

6. Svenskt Trä. KL-trähandbok. (Skogsindustrierna, Svenskt trä, 2017).

7. Brandner, R., Flatscher, G., Ringhofer, A., Schickhofer, G. \& Thiel, A. Cross laminated timber (CLT): overview and development. Eur. J. Wood Wood Prod. 74, 331-351 (2016).

8. Brandner, R. Production and Technology of Cross Laminated Timber (CLT): A state-of-the-art Report. Focus Solid Timber Solut. - Eur. Conf. Cross Laminated Timber 3-36 (2013).

9. Trätek. Bygga med massivträ $i$ Norden Ett. Kontenta (2002).
10. Bednar, T. \& Hagentoft, C.-E. IEA Annex 55 Reliability of Energy Efficient Building Retrofitting- Probability Assessment of Performance and Cost (RAP-RETRO) Risk management by probabilistic assessment. Development of guidelines for practice. (Chalmers University of Technology, Gothenburg, Sweden, 2015).

11. Svensson Tengberg, C. \& Hagentoft, C.-E. Implementing a framework for qualitative assessment of new technical solutions: A case study on CLT. in (Conference paper, Submitted, 2020).

12. Alsayegh, G., Mukhopadhyaya, P., Wang, J., Zalok, E. \& van Reenen, D. Preliminary Characterization of Physical Properties of CrossLaminated-Timber (CLT) Panels for Hygrothermal Modelling. Adv. Civ. Eng. Mater. 2, 472-484 (2013).

13. Lepage, R. T. M. Moisture Response of Wall Assemblies of Cross- Laminated Timber Construction in Cold Canadian Climates (Thesis). Civ. Eng. Universiy Waterloo, Ontario, Canada 139 pp (2012).

14. Yoo, J., Chang, S. J., Lee, J., Wi, S. \& Kim, S. Numerical analysis of hygrothermal properties and behavior of Korean based cross-laminated timber (CLT) wall system to deduce optimal assemblies. $J$. Clean. Prod. 213, 1217-1227 (2019).

15. Mukhopadhyaya, P., Bundalo-Perc, S., van Reenen, D. \& Wang, J. Mid-rise wood: Characterization of hygrothermal properties. doi:https://doi.org/10.4224/21274573

16. Fraunhofer IBP. WUFI. Available at: https://wufi.de/en/.

17. Karacabeyli, E. \& Douglas, B. Hand book cross laminated timber. Book (FPInnovations, 2013).

18. Teibinger, M. \& Matzinger, I. Construction with Cross-Laminated Timber in Multi-Storey Buildings: Focus on Building Physics. Holzforschung Austria (Holzforschung Austria, 2013).

19. Kordziel, S., Pei, S., Glass, S. V., Zelinka, S. \& Tabares-Velasco, P. C. Structure Moisture Monitoring of an 8-Story Mass Timber Building in the Pacific Northwest. J. Archit. Eng. 25, 04019019, 1-14 (2019).

20. McClung, R., Ge, H., Straube, J. \& Wang, J. Hygrothermal performance of cross-laminated timber wall assemblies with built-in moisture: Field measurements and simulations. Build. Environ. 71, 95-110 (2014).

21. Mustapha, G., Khondoker, K. \& Higgins, J. Moisture Performance and Vertical Movement Monitoring of Pre-Fabricated Cross Laminate Timber - Featured Case Study: Ubc Tallwood House. in CCBST 15th Canadian Confererence on Building Science and Technology paper 88 (2017).

22. Wang, J. Wetting and drying performance of woodbased assemblies related to on-site moisture management. in (World conference on Timber Engineering, Austria, 2016). 
23. Schmidt, E. \& Riggio, M. Monitoring moisture performance of cross-laminated timber building elements during construction. Buildings 9, (2019).

24. Olsson, L. Fuktsäkerhet vid KL-träbyggande utan väderskydd. (RISE / SBUF, 2019).

25. Serrano, E., Enquist, B. \& Vessby, J. Long term insitu measurements of displacement, temperature and relative humidity in a multi-storey residential CLT building. in WCTE 2014 - World Conference on Timber Engineering, Proceedings (2014).

26. Träbyggnadskansliet. Woodprint Sweden. Available at: http://woodprintsweden.se/. (Accessed: 12th January 2020) 